\title{
Reasons for Larger Warming Projections in the IPCC Third Assessment Report
}

\author{
T. M. L. WigLEY \\ National Center for Atmospheric Research,* Boulder, Colorado \\ S. C. B. RAPER \\ Climatic Research Unit, University of East Anglia, Norwich, Norfolk, United Kingdom, and Alfred Wegener Institute for \\ Polar and Marine Research, Bremerhaven, Germany
}

(Manuscript received 25 September 2001, in final form 11 April 2002)

\begin{abstract}
Projections of future warming in the Intergovernmental Panel on Climate Change (IPCC) Third Assessment Report (TAR) are substantially larger than those in the Second Assessment Report (SAR). The reasons for these differences are documented and quantified. Differences are divided into differences in the emissions scenarios and differences in the science (gas cycle, forcing, and climate models). The main source of emissions-related differences in warming is aerosol forcing, primarily due to large differences in $\mathrm{SO}_{2}$ emissions between the SAR and TAR scenarios. For any given emissions scenario, concentration projections based on SAR and TAR science are similar, except for methane at high emissions levels where TAR science leads to substantially lower concentrations. The new (TAR) science leads to slightly lower total forcing and slightly larger warming. At the low end of the warming range the effects of the new science and the new emissions scenarios are roughly equal. At the high end, TAR science has a smaller effect and the main reason for larger TAR warming is the use of a different high-end emissions scenario, primarily changes in $\mathrm{SO}_{2}$ emissions.
\end{abstract}

\section{Introduction}

In the Second Assessment Report (SAR) of the Intergovernmental Panel on Climate Change (IPCC), projections of global-mean temperature change over 19902100 under the IS92 "no climate policy" emissions scenarios (Leggett et al. 1992) ranged from $0.9^{\circ}$ to $3.5^{\circ} \mathrm{C}$ (Kattenberg et al. 1996). This range spans uncertainties in the climate sensitivity (equilibrium $\mathrm{CO}_{2}$-doubling temperature change, $\Delta T_{2 \times}$, of $1.5^{\circ}-4.5^{\circ} \mathrm{C}$ ) and in emissions (six scenarios) and uses central estimates for atmospheric composition change and radiative forcing. In the IPCC Third Assessment Report (TAR), the corresponding warming range spanning uncertainties in both sensitivity $\left(\Delta T_{2 \times}=1.7^{\circ}-4.2^{\circ} \mathrm{C}\right)$ and emissions [35 no climate policy SRES scenarios based on four "storylines"; Nakićenović and Swart (2000)] was $1.4^{\circ}-5.8^{\circ} \mathrm{C}$ (Cubasch and Meehl 2001). Why are the more recent projections so much larger?

The same climate model was used in both reports, the upwelling-diffusion, energy balance model (UD

* The National Center for Atmospheric Research is sponsored by the National Science Foundation.

Corresponding author address: Dr. T. M. L. Wigley, NCAR, P.O. Box 3000, Boulder, CO 80307.

E-mail: wigley@ucar.edu
EBM) of Wigley and Raper (1992) and Raper et al. (1996). However, the underlying emissions scenarios were quite different, and significant improvements were made in the way atmospheric composition changes were calculated from these emission scenarios and the way in which the climate model was applied. It is these factors that lead to the different warming projections. The purpose of this paper is to describe, explain, and quantify the effects of these two types of change, changes in emissions and changes in the science, and assess their relative importance.

Based on global-mean temperature response to 2100 , the lowest and highest emissions scenarios are IS92c and IS92e for the SAR case, and B1-IMA and A1C-MI for the TAR case. ["B1-IMA" here indicates a scenario from the B1 storyline developed using the IMAGE integrated assessment model (Alcamo et al. 1998)]. A1C$\mathrm{MI}$ is a coal-intensive member from the A1 storyline and was developed using the MiniCAM integrated assessment model (Edmonds et al. 1996). Since our primary goal is to explain the SAR to TAR differences in the range of temperature changes, we concentrate on results for these four scenarios. Note that A1C-MI is not one of the six "illustrative" scenarios selected by IPCC for more intensive analysis, although it comes from the same family as the A1FI scenario. Warming under the A1FI illustrative scenario is slightly less than for A1C-MI. 
TABLE 1. Midyear concentrations. In the TAR, observed concentrations were through the 1990s. These values differ slightly from those used in the SAR, but the radiative forcing effects of these differences are negligible. Note that $\mathrm{CO}_{2}$ projections based on TAR science include the effects of climate feedbacks on the carbon cycle, whose magnitudes are scenario and climate model dependent. Values in the top half of the table use lower-bound climate model parameters, while values in the lower half of the table use upper-bound climate model parameters.

\begin{tabular}{lllllll}
\hline \hline Row & Science & Scenario & Year & $\begin{array}{c}\mathrm{CO}_{2} \\
(\mathrm{ppm})\end{array}$ & $\begin{array}{l}\mathrm{CH}_{4} \\
(\mathrm{ppb})\end{array}$ & $\begin{array}{l}\mathrm{N}_{2} \mathrm{O} \\
(\mathrm{ppb})\end{array}$ \\
\hline 1 & SAR & IS92c & 2050 & 447.0 & $2147 *$ & $360.9 * *$ \\
2 & TAR & IS92c & 2050 & 450.1 & 2200 & 363.0 \\
3 & TAR & B1-IMA & 2050 & 489.2 & 1877 & 358.0 \\
\hline 4 & SAR & IS92c & 2100 & 472.1 & $1999 *$ & $386.6 * *$ \\
5 & TAR & IS92c & 2100 & 480.8 & 2109 & 388.8 \\
6 & TAR & B1-IMA & 2100 & 532.7 & 1568 & 376.0 \\
\hline 7 & SAR & IS92e & 2050 & 561.7 & $2959 *$ & $373.4 * *$ \\
8 & TAR & IS92e & 2050 & 563.6 & 2630 & 372.8 \\
9 & TAR & A1C-MI & 2050 & 578.0 & 2676 & 380.3 \\
\hline 10 & SAR & IS92e & 2100 & 948.9 & $4097 *$ & $429.2 * *$ \\
11 & TAR & IS92e & 2100 & 973.1 & 3398 & 427.2 \\
12 & TAR & A1C-MI & 2100 & 967.6 & 2989 & 461.3 \\
\hline
\end{tabular}

* The values shown are those used for the climate projections in the SAR (Kattenberg et al. 1996). These are 2\%-4\% lower than values given elsewhere in the SAR (Prather et al. 1996, his Table 2.5a), where a slightly different methane model was used.

** The values shown are those used for the climate projections in the SAR (Kattenberg et al. 1996). These are 3-4 ppb lower than values given elsewhere in the SAR (Prather et al. 1996, his Table $2.5 b)$, where slightly different $\mathrm{N}_{2} \mathrm{O}$ model was used.

We begin by considering the effects of differences in the emissions scenarios. We do this by comparing IS92c with B1-IMA and IS92e with A1C-MI using TAR science in both cases. Then, to assess the effects arising from SAR versus TAR science differences, we compare results for IS92c and IS92e based on SAR science with those based on TAR science. The SAR science results produced here are the same as those published in the SAR (Kattenberg et al. 1996). The SRES/TAR cases are those published in the TAR (Cubasch and Meehl 2001), except for a correction to tropospheric ozone abundances, explained below (see Table 4.11 in Prather and Ehhalt 2001). Finally, we summarize and discuss the results.

\section{Emissions differences}

To quantify the effects of emissions scenario differences between the SAR and the TAR, we use TAR science and compare concentration and forcing projections for the emissions scenarios with the lowest (IS92c versus B1-IMA) and highest (IS92e versus A1C-MI) warmings. At the low end, in terms of concentrations, B1-IMA has higher $\mathrm{CO}_{2}$ and lower $\mathrm{CH}_{4}$ concentrations than IS92c (Table 1, rows 2 and 3 for 2050 and rows 5 and 6 for 2100). $\mathrm{N}_{2} \mathrm{O}$ concentrations are slightly lower in B1-IMA. At the high end, $\mathrm{CO}_{2}$ concentrations for A1C-MI are remarkably similar to those in IS92e (Table 1 , rows 8 and 9 for 2050 and rows 11 and 12 for 2100). Note that, although A1C-MI has the highest 2100 total forcing in the SRES set (Table 2), it does not have the highest $\mathrm{CO}_{2}$ concentrations. For $\mathrm{CH}_{4}$, concentrations in the two high-end scenarios are very similar up to around 2050, after which A1C-MI concentrations become progressively less than IS92e (Table 1).

The biggest forcing differences between the two low scenarios are for $\mathrm{CO}_{2}$ (A1C-MI higher than IS92e), followed by sulfate aerosol forcing (cf. rows 2 and 3, and rows 5 and 6 in Table 2). For the two high scenarios the biggest differences are for sulfate aerosol forcing (row 8 versus 9 and 11 versus 12 in Table 2).

The large aerosol forcing differences arise because the SRES scenarios account for likely policy responses to sulfur pollution (i.e., to the adverse effects of such pollution on human health, food production, and ecosystems). This leads to substantially lower $\mathrm{SO}_{2}$ emissions than for the IS92 scenarios. Essentially, increasing affluence leads to greater awareness of these problems

TABLE 2. Radiative forcing from $1990\left(\mathrm{~W} \mathrm{~m}^{-2}\right)$. The $\mathrm{CH}_{4}$ forcing includes the effect of stratospheric water vapor changes from $\mathrm{CH}_{4}$ oxidation, and halocarbon forcing includes the effect of associated stratospheric ozone changes. Projections using TAR science include the effects of climate feedbacks on the carbon cycle (see Table 1 caption).

\begin{tabular}{|c|c|c|c|c|c|c|c|c|c|c|c|}
\hline Row & Science & Scenario & Year & $\begin{array}{c}\mathrm{CO}_{2} \\
(\mathrm{ppm})\end{array}$ & $\begin{array}{c}\mathrm{CH}_{4} \\
(\mathrm{ppb})\end{array}$ & $\begin{array}{l}\mathrm{N}_{2} \mathrm{O} \\
(\mathrm{ppb})\end{array}$ & Halocarb & $\begin{array}{l}\text { Tropospheric } \\
\text { ozone }\end{array}$ & $\begin{array}{c}\mathrm{SO}_{4} \\
\text { aerosol }\end{array}$ & Other aerosol & Total \\
\hline 1 & SAR & IS92c & 2050 & 1.476 & 0.162 & 0.192 & 0.210 & 0.037 & -0.162 & - & 1.914 \\
\hline 2 & TAR & IS92c & 2050 & 1.254 & 0.186 & 0.169 & 0.196 & 0.116 & -0.196 & -0.003 & 1.721 \\
\hline 3 & TAR & B1-IMA & 2050 & 1.687 & 0.067 & 0.154 & 0.120 & 0.051 & 0.026 & 0.128 & 2.233 \\
\hline 4 & SAR & IS92c & 2100 & 1.821 & 0.109 & 0.280 & 0.314 & 0.024 & 0.239 & - & 2.787 \\
\hline 5 & TAR & IS92c & 2100 & 1.597 & 0.154 & 0.244 & 0.278 & 0.056 & 0.284 & 0.051 & 2.662 \\
\hline 6 & TAR & B1-IMA & 2100 & 2.130 & -0.056 & 0.207 & 0.133 & -0.101 & 0.682 & 0.134 & 3.130 \\
\hline 7 & SAR & IS92e & 2050 & 2.916 & 0.428 & 0.236 & 0.210 & 0.107 & -1.108 & - & 2.787 \\
\hline 8 & TAR & IS92e & 2050 & 2.493 & 0.331 & 0.198 & 0.190 & 0.328 & -1.361 & 0.148 & 2.327 \\
\hline 9 & TAR & A1C-MI & 2050 & 2.628 & 0.346 & 0.219 & 0.183 & 0.626 & -0.014 & -0.061 & 3.927 \\
\hline 10 & SAR & IS92e & 2100 & 6.218 & 0.743 & 0.420 & 0.314 & 0.206 & -1.286 & - & 6.616 \\
\hline 11 & TAR & IS92e & 2100 & 5.416 & 0.561 & 0.352 & 0.264 & 0.602 & -1.584 & 0.289 & 5.899 \\
\hline 12 & TAR & A1C-MI & 2100 & 5.386 & 0.442 & 0.443 & 0.277 & 0.786 & 0.648 & 0.138 & 8.118 \\
\hline
\end{tabular}


TABLE 3. SAR vs TAR science; gas cycle and radiative forcing differences.

\begin{tabular}{|c|c|c|}
\hline Item & SAR & TAR \\
\hline Carbon cycle & Wigley (1993) model; no climate feedbacks. & Wigley (1993) model, with climate feedbacks. \\
\hline Methane & $\begin{array}{l}\text { Osborn and Wigley (1994) model including } \\
\mathrm{CH}_{4} \text { feedback, but not accounting for reac- } \\
\text { tive gas emissions. }\end{array}$ & $\begin{array}{l}\text { TAR model (Prather and Ehhalt 2001) accounting } \\
\text { for } \mathrm{CH}_{4} \text { feedback and reactive gas emissions. }\end{array}$ \\
\hline Nitrous oxide & Constant lifetime model $(\tau=120 \mathrm{yr})$ & $\begin{array}{l}\text { Minor change to SAR model leading to small } \\
\text { changes in lifetime (Prather and Ehhalt 2001). }\end{array}$ \\
\hline Tropospheric ozone & Related only to changes in $\mathrm{CH}_{4}$ concentration. & $\begin{array}{l}\text { Related to } \mathrm{CH}_{4} \text { concentrations and reactive gas } \\
\text { emissions changes (Prather and Ehhalt 2001). }\end{array}$ \\
\hline Halocarbons & $\begin{array}{l}\text { Constant lifetime models. Twenty-two species } \\
\text { and stratospheric ozone changes accounted } \\
\text { for. }\end{array}$ & $\begin{array}{l}\text { Variable lifetimes for hydrogenated gases. Thirty } \\
\text { species }\left(\mathrm{SF}_{6} \text { being the most important addition). }\right. \\
\text { Stratospheric ozone quantification changed slight- } \\
\text { ly. }\end{array}$ \\
\hline Sulfate aerosols & $\begin{array}{l}\text { Both direct and indirect forcing effects in- } \\
\text { cluded (see Harvey et al. 1997). } 1990 \\
\text { forcings: }-0.3 \text { and }-0.8 \mathrm{~W} \mathrm{~m}^{-2} \text {, respec- } \\
\text { tively. }\end{array}$ & $\begin{array}{l}\text { Both direct and indirect forcing as in SAR, but } 1990 \\
\text { direct forcing changed to }-0.4 \mathrm{~W} \mathrm{~m}^{-2} \text {. }\end{array}$ \\
\hline Other aerosols & $\begin{array}{l}\text { Carbonaceous aerosol lumped with direct sul- } \\
\text { fate aerosol forcing. Biomass aerosol }-0.2 \\
\mathrm{~W} \mathrm{~m}^{-2} \text { and assumed constant after } 1990 \text {. }\end{array}$ & $\begin{array}{l}\text { Fossil and organic carbonaceous aerosols lumped to- } \\
\text { gether, but considered separately from sulfate } \\
\text { aerosol }\left(1990 \text { level, }+0.1 \mathrm{~W} \mathrm{~m}^{-2}\right) \text {. Biomass aero- } \\
\text { sol as SAR to } 1990 \text {, and related to gross defores- } \\
\text { tation changes subsequently. }\end{array}$ \\
\hline Radiative forcing & $\begin{array}{l}\mathrm{CO}_{2} \text { used } \Delta Q=\alpha \ln \left(C / C_{0}\right) \text { with } \alpha=6.3 \text {. } \\
\mathrm{CH}_{4}, \mathrm{~N}_{2} \mathrm{O} \text {, and other gases as in SAR } \\
(\text { Shine et al. 1990). }\end{array}$ & $\begin{array}{l}\mathrm{CO}_{2} \text { forcing reduced with } \alpha \text { ranging from } 5.20 \text { to } \\
5.35 \text { (Cubasch and Meehl 2001). Small reduction } \\
\text { in } \mathrm{N}_{2} \mathrm{O} \text { forcing following Myhre et al. (1998). Mi- } \\
\text { nor changes to other gases. }\end{array}$ \\
\hline
\end{tabular}

and an increased ability to respond to them through the use of cleaner fuels and emissions control measures. Thus, in the SRES scenarios, the recent tightening of sulfur-control policies in Organization for Economic Cooperation and Development (OECD) countries is accounted for and it is assumed that sulfur emissions will also be increasingly controlled outside the OECD. Further details are given in Nakićenović and Swart (2000, 43, 44, and 149-153) and the issues are reviewed in Grubler (1998) and Smith et al. (2001). Lower sulfur emissions means less negative sulfate aerosol forcing (i.e., an increase in total forcing). Specifically, in 2100, B1-IMA aerosol forcing is $0.4 \mathrm{~W} \mathrm{~m}^{-2}$ greater than IS92c and $\mathrm{A} 1 \mathrm{C}-\mathrm{MI}$ aerosol forcing is $2.2 \mathrm{~W} \mathrm{~m}^{-2}$ greater than IS92e (Table 2).

There are also noticeable forcing differences for tropospheric ozone forcing in the high scenarios (A1C-MI higher than IS92e). By 2100, however, this difference is largely offset by differences in methane forcing (Table 2 , rows 11 and 12 ).

In terms of total radiative forcing over 1990-2100, if TAR gas cycle and forcing science is used in both cases to isolate the effect of emissions differences, the net effect of these differences is that B1-IMA forcing exceeds IS92c by around $0.5 \mathrm{~W} \mathrm{~m}^{-2}$ while A1C-MI exceeds IS92e by more than $2 \mathrm{~W} \mathrm{~m}^{-2}$ (Table 2). Changes in aerosol forcing are the main reason for these differences in total forcing.

\section{Science differences: Concentrations and forcing}

In this section, we consider IS92c and IS92e and compare their concentration and radiative forcing projec- tions using SAR science with those obtained using TAR science. The relevant differences in SAR and TAR science are summarized in Table 3 . Table 4 summarizes SAR versus TAR climate model differences, which will be considered in the next section.

From Table 3 it is clear that TAR gas cycle science is more sophisticated than that used in the SAR. However, the effects on concentration projections for any given emissions scenario are relatively small (see Table 1 , and cf. the SAR and TAR results for IS92c and IS92e). The largest relative differences in concentration are for methane projections under IS92e where the newer (TAR) gas cycle model, which incorporates the effects of reactive gas emissions on methane lifetime (Prather and Ehhalt 2001; Wigley et al. 2002), leads to substantially lower concentrations.

Table 2 summarizes the effects of SAR versus TAR gas cycle and forcing differences in terms of gas-bygas radiative forcing changes for IS92c and IS92e. By far the biggest SAR to TAR effect on forcing (for a given emissions scenario) is for $\mathrm{CO}_{2}$ (cf. rows " $n$ " and " $n+1$ " for $n=1,4,7$, and 10 in Table 2). This is because, in the TAR, the scaling factor between forcing and $\mathrm{CO}_{2}$ concentration change is $15 \%-17 \%$ less than that used in the SAR. However, as will be explained below, this reduction in $\mathrm{CO}_{2}$ forcing actually leads to increased warming. The next most important change is for tropospheric ozone, where the use of TAR science leads to larger forcing, notably so for IS92e. Total aerosol forcing for any given emissions scenario is very similar in both the TAR and SAR cases. The overall effect of using TAR rather than SAR science for the 
TABLE 4. SAR vs TAR science; climate model differences. TAR parameter values are those used for the low and high TAR extremes only. For further details see Cubasch and Meehl (2001, their appendix 9.1).

\begin{tabular}{|c|c|c|c|}
\hline Model parameter & SAR & TAR & SAR to TAR effect \\
\hline Sensitivity $\left(\Delta T_{2 \times}\right)$ & $1.5^{\circ}-4.5^{\circ} \mathrm{C}$ & $1.7^{\circ}-4.2^{\circ} \mathrm{C}$ & See text \\
\hline Land-ocean sensitivity ratio & 1.3 & $1.2-1.4$ & $-1 \%$ to $+2 \%$ \\
\hline Land-ocean exchange coefficient $\left[\mathrm{W} \mathrm{m}^{-2}\left({ }^{\circ} \mathrm{C}\right)^{-1}\right]$ & 1.0 & $0.5-1.0$ & $<1 \%$ \\
\hline 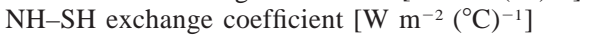 & 1.0 & $0.5-1.0$ & $<1 \%$ \\
\hline Mixed layer depth (m) & 90 & 60 & $-0 \%$ to $+2 \%$ \\
\hline$\pi *$ & 0.2 & 0.2 & - \\
\hline Initial upwelling rate $\left(\mathrm{m} \mathrm{yr}^{-1}\right)$ & 4.0 & 4.0 & - \\
\hline THC changes & Linearly related to $\Delta T$ & $\begin{array}{l}\text { Partitioned, with } 30 \% \\
\quad \text { linearly related to } \Delta T\end{array}$ & See text \\
\hline THC zero point temperature & $7^{\circ} \mathrm{C}$ & $8-14^{\circ} \mathrm{C}$ & See text \\
\hline Diffusivity $\left(\mathrm{cm}^{2} \mathrm{~s}^{-1}\right)$ & 1.0 & 2.3 & $-4 \%$ to $-15 \%$; see text \\
\hline Ice melt factor** & 1.0 & 1.25 & $+3 \%$ to $+8 \% ;$ see text \\
\hline
\end{tabular}

* Ratio of sinking water temperature change to global-mean temperature change.

**Factor to account for sea ice changes (see Raper et al. 2001). The 1.0 value indicates that this factor was not considered in the SAR.

IS92c and IS92e scenarios is a slight reduction in total forcing, arising mainly through the reduction in $\mathrm{CO}_{2}$ forcing.

These total forcing differences are illustrated in Fig. 1. For the low scenarios, the effects of differences in science (cf. the two $92 \mathrm{c}$ curves at the bottom of the plot) are about one-third the magnitude of the effects of differences in emissions [cf. the bold (lower) 92c curve with the B1 curve]-the science and emissions influences are in opposite directions. For the high scenarios,

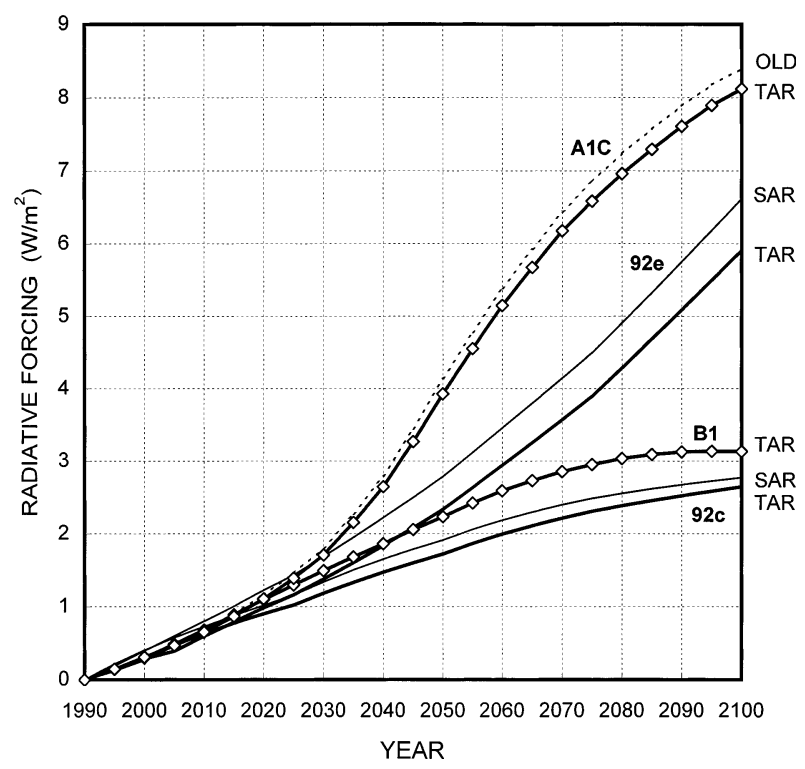

FIG. 1. Radiative forcing for low and high estimates of global-mean warming given in the IPCC SAR and TAR. The emission scenarios leading to low and high warming projections are IS92c (labeled 92c) and IS92e (92e) for the SAR (thin and thick continuous lines), and A1C-MI (labeled A1C) and B1-IMA (labeled B1) for the TAR (curves with diamonds). The upper limit used in the TAR is shown here as A1C-OLD; A1C-TAR corrects an error in tropospheric ozone projections. Comparing the two 92c curves or the two 92e curves shows the effect of changes in the science. Comparing the continuous thick and diamond curves (92c-TAR and B1-TAR, or 92e-TAR and A1CTAR) shows the effect of the different emission scenarios. science and emissions effects have the same relative importance as for the low scenarios, but their overall magnitude is much larger.

Figure 1 also shows the effect of correcting a minor error in the TAR formula for tropospheric ozone abundance (Prather and Ehhalt 2001). This was not discovered in time to be used in the TAR climate model calculations. It has a negligible effect at the low end not shown), but results in slightly lower forcing at the high scenario end [cf. A1C-OLD (dashed curve, giving the forcing as used in the TAR climate calculations) with A1C-TAR (bold with diamonds, giving the corrected forcing used here)].

It should be noted that neither gas cycle nor forcing uncertainties were explicitly accounted for in the TAR temperature projections. The most important of these are uncertainties in modeling the carbon cycle (primarily in quantifying feedback effects), and uncertainties in aerosol forcing. For further information and an assessment of the effects of these uncertainties, see the probabilistic warming analysis of Wigley and Raper (2001).

\section{Climate model differences}

The forcings in Fig. 1 are translated to global-mean temperature changes in Fig. 2. The SAR low and high extremes are 92c-SAR and 92e-SAR, while the TAR extremes are B1-TAR and A1C-TAR. (A1C-OLD gives the published TAR upper limit, prior to correction of the tropospheric ozone abundance formula.) Both 92cTAR and 92e-TAR give the transition results using SAR emissions extremes with TAR science.

Climate model parameter differences between the SAR and TAR are summarized in Table 4. As indicated in the table, a number of parameter changes have only a negligible effect on the temperature projections. Only those with significant effects are considered below. Two factors lead to increased warming: the relationship between $\mathrm{CO}_{2}$ concentration and forcing (this item is listed in Table 3); and changes in the way the assumed slow- 


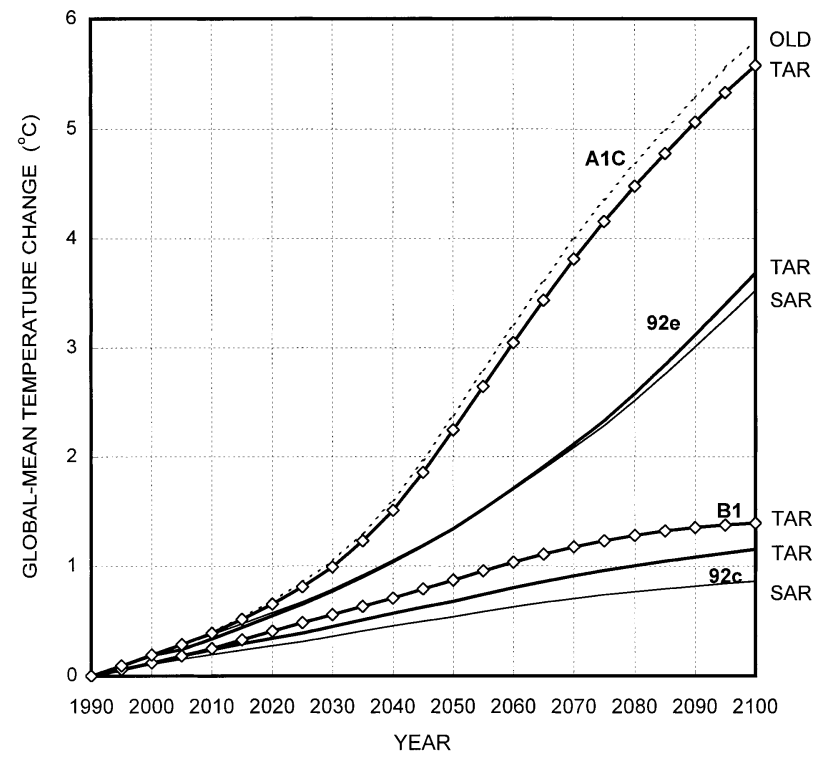

FIG. 2. Low and high estimates of global-mean warming given in the IPCC SAR and TAR. The emissions scenarios leading to low and high warming projections are IS92c (labeled 92c) and IS92e (labeled 92e) for the SAR (thin and thick continuous lines), and A1C-MI (labeled A1C) and B1-IMA (labeled B1) for the TAR (curves with diamonds). The published TAR upper limit is shown here as A1COLD; A1C-TAR corrects an error in tropospheric ozone projections. Comparing the two 92c curves or the two 92e curves shows the effect of changes in the science. Comparing the continuous thick and diamond curves (92c-TAR and B1-TAR, or 92e-TAR and A1C-TAR) shows the effect of the different emission scenarios.

down in the thermohaline circulation (THC) was modeled. Two other factors lead to decreased warming: the use of a larger value for the ocean's effective vertical diffusivity; and the introduction of a sea ice melt factor.

When the IS92 results in Figs. 1 and 2 are compared there is an apparently paradoxical result. For both IS92c and IS92e, TAR science forcing is less than SAR science forcing (Fig. 1); yet in both cases TAR science warming is greater than for SAR science (cf. either the two 92c curves or the two 92e curves in Fig. 2). At the low end, this is partly because TAR science uses a higher minimum sensitivity, namely, $1.7^{\circ} \mathrm{C}$, from the Parallel Climate Model (PCM) AOGCM (Washington et al. 2000; Raper et al. 2002), instead of $1.5^{\circ} \mathrm{C}$. This, however, cannot be the reason for the high emissions scenario (IS92e) since the high sensitivity used in the TAR $\left[4.2^{\circ} \mathrm{C}\right.$, from the Geophysical Fluid Dynamics Laboratory (GFDL) AOGCM; Stouffer and Manabe 1999; Raper et al. 2002] is actually less than the upper-bound value used in the $\operatorname{SAR}\left(4.5^{\circ} \mathrm{C}\right)$.

The reason for this switch (lower forcing giving higher warming) is partly because of changes in the relationship between $\mathrm{CO}_{2}$ concentration and radiative forcing (lower forcing for given concentration in the TAR), as explained below and in Wigley and Smith (1998), and partly because of the SAR versus TAR differences in the assumed rates of decline in the thermohaline circulation. We consider the $\mathrm{CO}_{2}$ forcing effect first.

\section{a. $\mathrm{CO}_{2}$ forcing effect}

The relationship between $\mathrm{CO}_{2}$ concentration $(\mathrm{C})$ and forcing is

$$
\Delta Q=\alpha \ln \left(C / C_{0}\right),
$$

where $\Delta Q$ is the forcing due to a concentration change from $C_{0}$ to $C$. In the energy balance climate model used for the IPCC projections, the value of $\alpha$ is specified by the user. The value used in the SAR was 6.3 (Shine et al. 1990). In the TAR, the lowest temperature projection used $\alpha=5.35$, while the highest projection used $\alpha=$ 5.20 (Cubasch and Meehl 2001, see their appendix 9.1). As already demonstrated, this reduces radiative forcing substantially. The effect on temperature of a change in $\alpha$, however, is quite different because of the structure of the climate model.

In the model, the climate sensitivity is defined by the equilibrium $\mathrm{CO}_{2}$-doubling temperature change $\left(\Delta T_{2 \times}\right)$. More generally, it should be defined by the equilibrium temperature change for a unit of radiative forcing change. We refer to this as the true sensitivity, $S$. Here $S$ and $\Delta T_{2 x}$ are related by

$$
S=\Delta T_{2 \times} / \Delta Q_{2 \times}
$$

where $\Delta Q_{2 \times}$ is the radiative forcing for $2 \times \mathrm{CO}_{2}\left[\Delta Q_{2 \times}\right.$ $=\alpha \ln (2)]$. It is $\Delta T_{2 \times}$ that is specified by the user rather than $S$. The $S$ is calculated internally in the model using $\Delta T_{2 \times}$ and $\alpha$.

If $\alpha$ is reduced (as in SAR to TAR) but $\Delta T_{2 \times}$ is not, then the radiative forcing due to $\mathrm{CO}_{2}$ is reduced, while the true climate sensitivity is increased. The net effect for $\mathrm{CO}_{2}$ is no change in equilibrium warming. For all forcing components other than $\mathrm{CO}_{2}$, however, the increased true sensitivity means that the temperature response is increased by a reduction in $\alpha$. Therefore, in the model used for the IPCC calculations, provided there is a significant non- $\mathrm{CO}_{2}$ component to forcing, reduced $\mathrm{CO}_{2}$ forcing can lead to greater warming.

To see this more clearly, suppose that a step change in forcing of magnitude $\Delta Q$ is imposed. The eventual equilibrium temperature change will then be

$$
\Delta T_{\text {equil }}=S \Delta Q=\Delta T_{2 \times}\{\Delta Q /[\alpha \ln (2)]\} .
$$

If $\alpha$ is reduced (the SAR to TAR reduction is $15 \%-$ $17 \%)$ and $\Delta T_{2 \times}$ remains unchanged, then, for fixed $\Delta Q$ (i.e., the case appropriate for the non- $\mathrm{CO}_{2}$ component of forcing) the above relationship shows that the equilibrium temperature change will be increased. If the forcing were due solely to $\mathrm{CO}_{2}$, however, then $\Delta Q$ and $\alpha$ would change by the same amount so there would be no effect on the equilibrium temperature response. As noted by Wigley and Smith (1998) this effect is partly offset for transient temperature changes because a change in $\alpha$ also changes the response time of the model 
TABle 5. Temperature $\left({ }^{\circ} \mathrm{C}\right)$ changes from 1990. For IS92c and IS92e, "low" and "high" refer to use of $1.5^{\circ}$ and $4.5^{\circ} \mathrm{C}$ sensitivity, respectively. For B1-IMA, model low refers to PCM $\left(\Delta T_{2 \times}=1.7^{\circ} \mathrm{C}\right)$, which gives the lowest warming projection; while for A1C-MI, model high refers to GFDL $\left(\Delta T_{2 \times}=4.2^{\circ} \mathrm{C}\right)$, which gives the highest warming projection. Warming results are given for both declining and constant thermohaline circulation intensity ("variable THC" and "constant THC"); see text. Numbers in italics denote the low SAR and TAR extremes, and numbers in bold denote the high SAR and TAR extremes.

\begin{tabular}{|c|c|c|c|c|c|c|c|}
\hline Row & Science & Base scenario & $\mathrm{SO}_{2}$ scenario & Year & Climate model & $\begin{array}{c}\text { Warming } \\
\text { (variable THC) }\end{array}$ & $\begin{array}{c}\text { Warming } \\
\text { (constant THC) }\end{array}$ \\
\hline 1 & SAR & IS92c & IS92c & 2050 & Low & 0.537 & 0.594 \\
\hline 2 & TAR & IS92c & IS92c & 2050 & Low & 0.678 & 0.697 \\
\hline 3 & TAR & B1-IMA & IS92c & 2050 & Low & 0.783 & 0.804 \\
\hline 4 & TAR & B1-IMA & B1-IMA & 2050 & Low & 0.871 & 0.896 \\
\hline 5 & SAR & IS92c & IS92c & 2100 & Low & 0.866 & 0.944 \\
\hline 6 & TAR & IS92c & IS92c & 2100 & Low & 1.158 & 1.191 \\
\hline 7 & TAR & B1-IMA & IS92c & 2100 & Low & 1.206 & 1.240 \\
\hline 8 & TAR & B1-IMA & B1-IMA & 2100 & Low & 1.391 & 1.430 \\
\hline 9 & SAR & IS92e & IS92e & 2050 & High & 1.334 & 1.701 \\
\hline 10 & TAR & IS92e & IS92e & 2050 & High & 1.336 & 1.461 \\
\hline 11 & TAR & A1C-MI & IS92e & 2050 & High & 1.510 & 1.637 \\
\hline 12 & TAR & A1C-MI & A1C-MI & 2050 & High & 2.244 & 2.426 \\
\hline 13 & SAR & IS92e & IS92e & 2100 & High & 3.526 & 4.457 \\
\hline 14 & TAR & IS92e & IS92e & 2100 & High & 3.684 & 4.036 \\
\hline 15 & TAR & A1C-MI & IS92e & 2100 & High & 3.966 & 4.351 \\
\hline 16 & TAR & A1C-MI & A1C-MI & 2100 & High & $5.576 *$ & 6.136 \\
\hline
\end{tabular}

* This is lower than the TAR upper bound (which is $5.8^{\circ} \mathrm{C}$ ) because we have corrected an error in the relationship for tropospheric ozone abundance.

(smaller $\alpha$ leads to greater $S$ and, hence, a slightly larger response time). The overall effect, however, is dominated by the equilibrium result.

\section{b. THC changes}

The $\mathrm{CO}_{2}$ forcing influence is amplified by the SAR to TAR changes in the assumed rates of slowdown in the THC. In the SAR, it was assumed that the THC (characterized in the SAR by the oceanic vertical circulation or the upwelling rate term in the model) would decline linearly with global-mean temperature change to reach zero at a "zero point" of $7^{\circ} \mathrm{C}$ (based on AOGCM results available at the time; see Kattenberg et al. 1996). In the TAR, the climate model's vertical circulation was divided into a climate-dependent THC component (30\%) and a second component that parameterized all heat flux processes other than those captured by the model's vertical diffusivity term (Cubasch and Meehl 2001, see their appendix 9.1). In the SAR, the model's vertical circulation term was assumed to be fully climate dependent.

A major methodological difference between the SAR and the TAR is that, in the TAR, the simple model was carefully calibrated to emulate results for seven different AOGCMs for a standard forcing experiment [a $1 \% \mathrm{yr}^{-1}$ compound increase in $\mathrm{CO}_{2}$ concentration from the Second Coupled Model Intercomparison Project (CMIP2; Raper et al. 2001)]. Each of the seven models required using different UD EBM parameters, within their ranges of uncertainty (Cubasch and Meehl 2001, see their appendix 9.1). The partitioning of the model's vertical circulation described above was found to be necessary in order to be able to match both oceanic thermal expansion and surface temperature changes in the AOGCMs. In the UD EBM calibration process, there was no "tuning" of the THC changes; that is, the actual changes observed in the AOGCMs were used directly in the UD EBM. Furthermore, the zero point temperature for the THC was specified directly from the results for each AOGCM; for the low projection model it was $14^{\circ} \mathrm{C}$, while for the high projection model it was $8^{\circ} \mathrm{C}$. The net result of partitioning the model's upwelling term and the higher zero point temperatures is that, in the TAR simulations, the rate at which the THC is assumed to slow down is much less than assumed in the SAR, consistent with recent AOGCM results.

A slowdown in the THC affects both the rate of formation of deep water in high latitudes, and the compensating rate of upwelling of cold water from the ocean depths. These changes in turn influence the net heat flux into the deep ocean, and act to shift the vertical temperature profile toward a new steady state. The overall effect of these processes is to change the rate of surface warming, with a reduced warming rate if there is an accompanying THC slowdown. Thus, a less rapid THC slowdown (as in the TAR cases) leads to more rapid warming. The magnitude of this effect is illustrated in Table 5 by giving warming results, not only for the slowdown rates used in the SAR and TAR, but also for the constant THC case. In the SAR, the assumed THC slowdown decreases the warming by $8 \%-22 \%$. In the TAR, the corresponding decrease is only 3\%-9\%. Hence, all other things being equal, TAR temperature 
changes would be greater than those based on SAR science.

\section{c. Diffusivity and sea ice effects}

The previous two sections explained how changes in the forcing for a $\mathrm{CO}_{2}$ doubling and a reduced rate of THC slowdown, both led to greater warming in the TAR. Slightly modifying these increases are the SARto-TAR changes in the ocean model's vertical diffusivity (which parameterizes cross- and along-isopycnal mixing) and the incorporation of a sea ice melt factor in the TAR model (Raper and Cubasch 1996; Raper et al. 2001). The magnitudes of these effects (cooling and warming, respectively) are determined here by simple sensitivity studies with the climate model (see Table 4). Their magnitudes depend on the climate sensitivity, being relatively more important at higher sensitivity, and the range of values in Table 4 largely reflects this dependence. The effects are only weakly dependent on emissions scenario and time.

The separation of the effects of SAR to TAR differences in THC changes and vertical diffusivity implied by this analysis is somewhat artificial because of the coupling of these factors in the process of calibrating the UD EBM against the different AOGCMs. In this calibration, UD EBM THC changes were defined directly from the results for each AOGCM using a single value (i.e., the same for each AOGCM) for the partitioning of the upwelling rate term into climate-related and other oceanic heat flux processes. Diffusivity was then determined in a way that effectively matched the UD EBM's total heat flux into the ocean to that for the AOGCM; heat flux into the ocean being determined in the UD EBM jointly by the upwelling rate and vertical diffusivity terms in the model. THC changes and vertical diffusivity are therefore not independent parameters. For example, if a different partitioning of the upwelling rate or a different rate of slowdown of the THC had been assumed, this would have been compensated for in the calibration process by a different value for the vertical diffusivity.

\section{d. $\mathrm{SO}_{2}$ emissions effects}

When all (gas cycle, forcing, and climate) model differences between the SAR and the TAR are accounted for, TAR warming projections for the emissions scenarios considered here are slightly greater than those based on SAR science (cf. the two 92c curves or the two 92e curves in Fig. 2). For the low-emissions cases, the effect of changes in the science has the same sign and is of similar magnitude to the effect of the emissions changes (cf. the 92c-SAR to 92c-TAR "science" difference with the 92c-TAR to B1-TAR "emissions" difference in Fig. 2). For the high-emissions cases, however, the dominant effect on warming comes through the change in emissions (cf. the 92e-SAR to 92e-TAR science difference with the 92e-TAR to A1C-TAR emissions difference in Fig. 2).

It was noted earlier that the main influence of emissions differences arises through $\mathrm{SO}_{2}$ and the resultant sulfate aerosol forcing. To quantify the specific role of sulfate aerosol forcing changes we consider a set of intermediate cases, all based on TAR science, where all emissions except $\mathrm{SO}_{2}$ are changed. For the low-end projections, we compare three sets of warming results: IS92c (Table 5, row 2 for 2050 results and row 6 for 2100 results); B1-IMA with IS92 $\mathrm{C} \mathrm{SO}_{2}$ emissions (rows 3 and 7); and the full B1-IMA scenario (rows 4 and 8). The difference between B1-IMA with old (IS92c) and new (B1-IMA) $\mathrm{SO}_{2}$ emissions isolates the effect of changing $\mathrm{SO}_{2}$ emissions. As a percentage of the change from IS92c (TAR science) to B1-IMA, the $\mathrm{SO}_{2}$ emissions component represents $46 \%$ of the emissions-related 1990-2050 warming differential and 79\% of the corresponding 1990-2100 warming differential.

At the high end we compare IS92e (TAR science), A1C-MI with IS92e $\mathrm{SO}_{2}$ emissions, and the full A1CMI scenario (see Table 5). $\mathrm{SO}_{2}$ emissions changes account for $81 \%$ of the emissions-related 1990-2050 warming differential, and $85 \%$ of the corresponding 1990-2100 warming differential.

\section{Summary and conclusions}

While the basic science underlying projections in global-mean temperature in the SAR and the TAR is the same, there are many differences in detail, spanning gas cycle models, radiative forcing formulas, and parameters in the climate model. Many of these changes in detail interact, in the sense that the influence of a particular change depends on the values assumed for other model characteristics or parameters. It is therefore difficult to categorically assign SAR-to-TAR differences quantitatively to specific factors.

We have divided the various factors into differences in the science and differences in the input emissions scenarios. Science differences lead to TAR radiative forcings for both the low and high scenarios being slightly less than those based on SAR science. When these forcings are used to drive the climate model, however, TAR warming results are slightly higher than SARbased results. This arises from compensating negative and positive influences that are, by themselves, appreciable in magnitude. At the low warming limit, TAR science inflates the 1990-2100 warming for the IS92c scenario by around $34 \%$. At the high end, TAR science inflates the 1990-2100 warming for the IS92e scenario by around $4 \%$.

When emissions scenario differences are accounted for, additional differences between the SAR and the TAR projections become evident, particularly at the high warming end. These arise mainly through differences in aerosol forcing, in turn, primarily due to differences in $\mathrm{SO}_{2}$ emissions. At the low end (based on 
TAR science) the use of the B1-IMA emissions scenario (replacing IS92c) increases the lower bound 1990-2100 warming by approximately $20 \%$. Using A1C-MI emissions in place of IS92e has a much more dramatic effect, increasing the upper bound warming by some $70 \%$. (The increase is slightly greater in the original TAR results, since the projections here use revised, and slightly lower, projections for future tropospheric ozone abundance.) For the lower-bound SAR to TAR increase in 19902100 warming, $0.87^{\circ}-1.39^{\circ} \mathrm{C}, 35 \%$ can be attributed to $\mathrm{SO}_{2}$ emissions changes. (This is much less than the $\mathrm{SO}_{2}$ fraction of the emissions-related component of change, because, at the low end, emissions-related changes account for less than half of the overall change.) For the upper-bound increase of $3.53^{\circ}-5.58^{\circ} \mathrm{C}$, where science changes play a very minor role, $79 \%$ of the increase arises from $\mathrm{SO}_{2}$ emissions changes.

While emissions scenario changes are the primary reason for the higher projections of global-mean warming in the TAR, this should not be interpreted as an indication that aspects of uncertainty in the science are of lesser importance. The range of projected warming is as much dependent on uncertainties in the climate sensitivity as it is on emissions uncertainties; and other factors can have noticeable influences on the extremes of projections (Wigley and Raper 2001) and on the spatial details of future climate change. The higher warming in the TAR, since it is at least partly the result of differences between the IS92 and SRES emissions scenarios, clearly reflects the difficulties inherent in defining future emissions. It does, nevertheless, also reflect progress in our ability to model these emissions, particularly $\mathrm{SO}_{2}$ emissions, more credibly.

Acknowledgments. This work was supported by the U.K. Department of the Environment, Transport and the Regions, HGF Strategiefonds-Projekt 2000/13 (SEAL Project), and ACACIA, a joint activity of EPRI and NCAR. Comments from Mike MacCracken helped improve the paper.

\section{REFERENCES}

Alcamo, J., E. Kreileman, and R. Leemans, Eds., 1998: Global Change Scenarios of the 21st Century: Results from the IMAGE 2.1 Model. Elsevier Science, 296 pp.

Cubasch, U., and G. A. Meehl, 2001: Projections for future climate change. Climate Change 2001: The Scientific Basis, J. T. Houghton et al., Eds., Cambridge University Press, 525-582.

Edmonds, J., M. Wise, H. Pitcher, R. Richels, T. M. L. Wigley, and C. MacCracken, 1996: An integrated assessment of climate change and the accelerated introduction of advanced energy technologies: An application of MiniCAM 1.0. Mitigation Adapt. Strat. Global Change, 1, 311-339.

Grubler, A., 1998: A review of global and regional sulfur emission scenarios. Mitigation Adapt. Strat. Global Change, 3, 383-418.
Harvey, L. D. D., and Coauthors, 1997: An introduction to simple climate models used in the IPCC second assessment report. IPCC Tech. Paper 2, Intergovernmental Panel on Climate Change, 50 pp.

Kattenberg, A., and Coauthors, 1996: Climate models-Projections of future climate. Climate Change 1995: The Science of Climate Change, J. T. Houghton et al., Eds., Cambridge University Press, 285-357.

Leggett, J. A., W. J. Pepper, and R. J. Swart, 1992: Emissions scenarios for IPCC: An update. Climate Change 1992: The Supplementary Report to the IPCC Scientific Assessment, J. T. Houghton et al., Eds., Cambridge University Press, 69-95.

Myhre, G., E. J. Highwood, K. P. Shine, and F. Stordal, 1998: New estimates of radiative forcing due to well mixed greenhouse gases. Geophys. Res. Lett., 25, 2715-2718.

Nakićenović, N., and R. Swart, Eds., 2000: Special Report on Emissions Scenarios. Cambridge University Press, $570 \mathrm{pp}$.

Osborn, T. J., and T. M. L. Wigley, 1994: A simple model for estimating methane concentration and lifetime variations. Climate Dyn., 9, 181-193.

Prather, M., and D. Ehhalt, 2001: Atmospheric chemistry and greenhouse gases. Climate Change 2001: The Scientific Basis, J. T. Houghton et al., Eds., Cambridge University Press, 239-287.

- R. Rerwent, D. Ehhalt, P. Fraser, E. Sanhueza, and X. Zhou, 1996: Other trace gases and atmospheric chemistry. Climate Change 1995: The Science of Climate Change, J. T. Houghton et al., Eds., Cambridge University Press, 86-103.

Raper, S. C. B., and U. Cubasch, 1996: Emulation of the results from a coupled general circulation model using a simple climate model. Geophys. Res. Lett., 23, 1107-1110.

— T. M. L. Wigley, and R. A. Warrick, 1996: Global sea level rise: Past and future. Sea-Level Rise and Coastal Subsidence: Causes, Consequences and Strategies, J. Milliman and B. U. Haq, Eds., Kluwer Academic, 11-45.

_ _ J. M. Gregory, and T. J. Osborn, 2001: Use of an upwellingdiffusion energy balance climate model to simulate and diagnose A/OGCM results. Climate Dyn., 17, 601-613.

,-- , and R. J. Stouffer, 2002: The role of climate sensitivity and ocean heat uptake on AOGCM transient temperature response. J. Climate, 15, 124-130.

Shine, K. P., R. G. Derwent, D. J. Wuebbles, and J.-J. Morcrette, 1990: Radiative forcing of climate. Climate Change: The IPCC Scientific Assessment, J. T. Houghton et al., Eds., Cambridge University Press, 41-68.

Smith, S. J., H. Pitcher, and T. M. L. Wigley, 2001: Global and regional anthropogenic sulfur dioxide emissions. Global Planet. Change, 29, 99-119.

Stouffer, R. J., and S. Manabe, 1999: Response of a coupled oceanatmosphere model to increasing atmospheric carbon dioxide: Sensitivity to the rate of increase. J. Climate, 12, 2224-2237.

Washington, W. M., and Coauthors, 2000: Parallel climate model (PCM) control and transient simulations. Climate Dyn., 16, 755774.

Wigley, T. M. L., 1993: Balancing the carbon budget: Implications for projections of future carbon dioxide concentration changes. Tellus, 45B, 409-425.

_ , and S. C. B. Raper, 1992: Implications for climate and sea level of revised IPCC emissions scenarios. Nature, 357, 293 300 .

— global-mean temperature change. Do We Understand Climate Change?, Norwegian Academy of Technological Sciences, 185195.

, and S. C. B. Raper, 2001: Interpretation of high projections for global-mean warming. Science, 293, 451-454.

- S. J. Smith, and M. J. Prather, 2002: Radiative forcing due to reactive gas emissions. J. Climate, 15, 2690-2696. 